\title{
Estudo da Viabilidade de Implantação de um Roteiro Turístico com Ênfase ao Turismo Cemiterial
}

\author{
The Feasibility Study of a Sightseeing Tour Implantation with Emphasis on Cemetery \\ Tourism
}

\author{
Luciana Rodrigues Souto, Nara Rejane Zamberlan dos Santos, Hamilton Munari Vogel \\ e Mirla Andrade weber
}

Unipampa- campus São Gabriel, RS, Brasil

narazamberlan@gmail.com; hamiltonvogel@uipampa.edu.br; mirlaweber@unipampa.edu.br

\begin{abstract}
Resumo
Os espaços cemiteriais, na modernidade, podem ser entendidos como locais de reflexão visto que vivemos em um mundo onde existem profundas transformações. O espaço do cemitério de São Gabriel-RS foi objeto de estudo bem como outros locais da cidade relacionados ao enterramento de pessoas, como a Capela dos Fuzilados, a Capela dos "Noivinhos" e o Nicho Funerário com os restos mortais do Monsenhor Henrique Rech, na Igreja Matriz, com a finalidade de uma leitura de sua história, bens patrimoniais e através de seus atrativos, bem como, verificar a possibilidade de ações para a valorização destes locais para compor um roteiro turístico para o município. Amparado por revisão bibliográfica, visitas ao local e documentação a pesquisa se desenvolveu no sítio principal da cidade - cemitério, mais locais da malha urbana onde admite-se encontrar enterradas pessoas que se tornaram santos populares no imaginário coletivo. Os dados coletados correspondem à expectativa de locais de elevado valor cultural, histórico e patrimonial, porém apontam a necessidade de iniciativas públicas elou privadas tanto para a salvaguarda deste patrimônio como da possibilidade de exploração como roteiro turístico da cidade.
\end{abstract}

Palavras Chave: Memória social. Cemitérios. patrimônio.

\begin{abstract}
The cemeteries, nowadays, can be understood as places for reflections since we've lived in a world with profound transformations. The cemetery space from São Gabriel-RS was the object of study as well as another burial places in the city as Capela dos Fuzilados and Capela dos Noivinhos and the funerary niche with the monsignor Henrique Rech remains, at Matriz Church, for the purpose of a history reading, assets and throught their attractives, check the possibility of actions for valuation of those places to make a city sightseeing tour. Based on literature review, place visits and documentation, the research developed at the city main site-cemetery, more places of the city where it's admitted to find buried people who became popular saints in the collective imagination. The collected data matches to expectation of high valued cultural, historical and patrimonial places, however it points to a need of public or private initiatives both to this patrimony safeguard and to the possibility of exploration as a city sightseeing tour.
\end{abstract}

Keywords: Social memory. cemeteries. patrimony. 


\section{Introdução}

Os cemitérios são locais de memória, que nos revelam histórias, que representam as dores, medos e sensações individuais, mas que também refletem o simbolismo dos grupos sociais.

Ao longo do tempo, cada civilização apresentou sua resposta para o problema da morte. Sepulturas, túmulo, pirâmides, catacumbas, cremação, ritos funerários, foram usados pelas sociedades como formas de destinar os restos mortais dos seus membros (Chiavenato, 1998).

O túmulo, segundo Carvalho (2010) conserva os restos mortais daqueles que fundaram e construíram o espaço urbano do qual usufruímos e perpetuam ainda a memória coletiva, tornaram-se vultos, citados na nominação das ruas, dos parques, dos bairros, das escolas e hospitais. No espaço dos cemitérios estão não somente seus corpos, mas a possibilidade de se resgatar a sua história e ressignificar a nossa própria. Sentimo-nos de certa forma curiosos, satisfeitos e angustiados em presenciar o túmulo como uma evidência daquilo que foi fato. De certa maneira, o indivíduo vê a si próprio diante do túmulo, compreendendo o fím da sua existência, todavia, pode ser lembrado, resgatado do anonimato.

Conforme Thompson (2014) "a visita ao cemitério é responsável por desenvolver a lembrança, e tudo que é lembrado se mantém vivo no meio social. Portanto, a memória mantém o morto vivo. Dessa forma, ir ao cemitério e lembrar-se dos mortos como sendo seres vivos faz a vida ser comemorada, exaltando a ideia de continuidade".

Ao considerarmos o túmulo como um objeto rico em valor estético, material e histórico, se trabalha com a memória da cidade e com toda uma rede relacional, que envolve as marmorarias (comércio), as comunidades religiosas, os representantes políticos, o papel dos falecidos, a atuação das famílias e mesmo a necessidade da mão de obra artística (Carvalho, 2010). Segundo o mesmo autor também se constitui campos de estudo para arte e para história, pois as necrópoles são subsídios de pesquisa para diversas áreas, como por exemplo, antropologia, arqueologia, geografia, genealogia, dentre outras. A versatilidade dos cemitérios como fontes de informações e a identidade cultural que preservam, convidam a pensar sobre seu valor patrimonial.

O patrimônio cultural material, principalmente os monumentos, exprime uma das funções essenciais do espírito: a memória, que está impregnada nos edifícios, nas representações, nos símbolos urbanos e rurais que evocam, perpetuam e recordam o passado (Carrasco, 2009).

A proteção é uma das ações mais importantes quando tratamos do patrimônio de natureza material. Proteger um bem cultural significa impedir que ele desapareça, mantendo-o preservado para as gerações futuras (IPHAN, 2015).

Assim, conforme Melo e Neto (2015), “o lugar de memória é funcional, pois gera concomitantemente a cristalização e a transmissão da lembrança. Esse lugar bloqueia o esquecimento e torna material o que é imaterial, levando à cristalização da memória, isto é, do passado. Em suma, são locais com aspectos imateriais ou materiais que abrigam a memória de uma sociedade ou de uma nação. Portanto, é nesses locais que os grupos se identificam e se reconhecem como grupo, o que promove a formação da identidade e a ideia de pertencimento".

Considerando que o meio mais eficaz de assegurar a defesa permanente do patrimônio de arte e de história do país é a educação popular, Brandão (1996) propõe "ações destinadas a proporcionar à comunidade os meios para participar, em todos os níveis, do processo educacional, de modo a garantir que a apreensão de outros conteúdos culturais se faça a partir dos valores próprios da comunidade. A participação referida se efetivará através da interação do processo educacional às demais dimensões da vida comunitária e da geração e operacionalização de situações de aprendizagem com base no repertório regional e local”.

Neste sentido, o Decreto Lei $\mathrm{n}^{\mathrm{o}} 25$, de 30 de novembro de 1937 , é o primeiro instrumento legal de 
proteção do patrimônio cultural no Brasil e nas Américas e seus preceitos fundamentais se mantêm atuais e em uso até os nossos dias. Pelo Decreto Lei 25, o patrimônio nacional é definido como "conjunto de bens móveis e imóveis existentes no país e cuja conservação é de interesse público, quer por sua vinculação a fatos memoráveis da história do Brasil, quer por seu excepcional valor arqueológico ou etnográfico, bibliográfico ou artístico" (BRASIL, 1937). A Constituição Brasileira também estabelece que cabe ao poder público, isto é, União, Estados e Municípios com o apoio da comunidade, a proteção, preservação e gestão do patrimônio cultural do país (BRASIL, 2008).

Os cemitérios por serem bens culturais buscam guarida em Meneses (1996) ao situar que "a cultura engloba tanto aspectos materiais como não materiais e se encarna na realidade empírica da existência cotidiana: tais sentidos, ao invés de meras elucubrações mentais, são parte essencial das representações com as quais alimentamos e orientamos nossa prática e, lançando mão de suportes materiais e não materiais, procuramos produzir inteligibilidade e reelaboramos simbolicamente as estruturas materiais de organização social, legitimando-as, reforçando-as e transformando".

O turismo cemiterial é uma prática ainda em desenvolvimento no Rio Grande do Sul, mas que felizmente tem encontrado receptividade por parte de alguns cemitérios, a exemplo das necrópoles da Santa Casa e a da Comunidade Evangélica de Porto de Alegre. Este tipo de turismo tem atraído grande número de público, como foi comprovado em duas edições de um passeio às necrópoles, promovido pela Prefeitura Municipal da capital gaúcha, pelo Programa Viva o Centro a Pé. Na primeira edição foram 150 participantes, e na segunda, cerca de 300 pessoas, o que demonstra interesse crescente. As visitas guiadas aos cemitérios revitalizam seu patrimônio ao aproximar a comunidade, que passa a vivenciar o espaço cemiterial de forma apreciativa e interessada (Carvalho, 2010).
Não se deve cogitar o turismo cemiterial, como algo recente, pois para Del Puerto; Baptista e Müller (2014) o primeiro guia turístico impresso da história surgiu no século XII e indicava aos peregrinos, o caminho do sepulcro do apostolo Tiago, em Santiago de Compostela.

A morte, segundo Castro (2008), mudou de forma significativa nas últimas décadas, embora continue, porém em menor proporção, certo distanciamento das questões relacionadas com os cultos dos mortos, pois na atualidade os cemitérios parecem se reintegrar como lugar na cidade, para outras visitas. Conforme a autora hoje estão presentes em roteiros histórico-culturais, e se transformaram em um dos muitos lugares destacados para se conhecer em uma cidade, a exemplo de Paris, Buenos Aires, Joinville e São Paulo que apresentam como opções de turismo cultural, um local onde se pode encontrar parte da memória da cidade a qual pertence.

São Gabriel é um município que contribuiu muito para a história do Rio Grande Sul, berço de grandes personagens que fizeram e fazem a história não somente do Estado, mas também do país (São Gabriel, 2015).

O Plano Diretor de São Gabriel prevê áreas de interesse histórico, mas não ocorreram tombamentos em termos quantitativos a não ser a Igreja do Rosário e Bom Fim, conhecida como "Igreja do Galo", o Sobrado da Praça e o Teatro Harmonia (ainda em obras) (São Gabriel, 2008).

Mesmo com toda esta riqueza patrimonial o turismo não possui nenhum destaque. Não são divulgadas ou propostas ações a respeito do patrimônio, lidas campeiras, folclore, crenças populares, entre outras.

A cidade de São Gabriel é rota permanente de argentinos e uruguaios que se hospedam para pernoitar e após seguirem rumo ao litoral gaúcho e catarinense. Segundo dados da Secretaria Municipal de Turismo (São Gabriel, 2015) foram atendidos apenas no ano de 2015 cerca de 2000 argentinos e uruguaios no Posto de Informações Turísticas montado às margens da BR 290, desconsiderando aqueles que pelo conhecimento 
preexistente não recorreram ao Posto de Informações.

Se estes turistas resolvem passar mais que uma noite na cidade quais são os atrativos que eles encontrarão?

Nestes países a arte cemiterial é altamente explorada a exemplo do Cemitério da Recoleta em Buenos Aires e o Cemitério Central de Montevidéu. O Cemitério da Recoleta é um importante atrativo na cidade de Buenos Aires, na Argentina. O diferencial desse cemitério é a forma em que os mortos são sepultados dentro dos mausoléus. O caixão não é enterrado e fica em destaque para apreciação do público. Depois de certo tempo, esses restos mortais são transferidos para caixas menores e dispostos novamente para que sejam visualizados. $\mathrm{O}$ cemitério abriga formas diversas de obras de arte, estimulando a visita de inúmeras pessoas que vêem o local como um museu a céu aberto. Os jardins que rodeiam o cemitério também são aproveitados pela maioria dos seus moradores para a prática de lazer (Monteiro et al, 2010), enquanto o Cemitério Central possibilita também um passeio através de sua história. No Panteão Nacional se resguardam os restos de figuras emblemáticas da cultura e da política uruguaia como José Enrique Rodó, Pedro Figari e de muitos presidentes.

Como em qualquer outro segmento do turismo é preciso conhecer sua composição, necessidades e perspectivas para que sua prática gere satisfação para o visitante e ao mesmo tempo promova desenvolvimento econômico sustentável para a localidade que o abriga (Monteiro et al, 2010).

O Cemitério Municipal da Irmandade da Santa Casa de São Gabriel, nem os outros locais citados anteriormente nunca foi cogitado como roteiro turístico, talvez por desinteresse ou tabu.

Porque o Cemitério Municipal da Irmandade de São Gabriel e demais pontos de enterramento de pessoas que fizeram e fazem parte da nossa história não podem ser o início de rotas turísticas?
Diante das opiniões dos autores supracitados e ainda baseado em Del Puerto; Baptista e Müller (2014) que ressignificar o cemitério através da atividade turística proporciona outras formas de percepção do espaço cemiterial e do mercado turístico. $O$ turismo nas necrópoles surge como um nicho de mercado para aqueles turistas que buscam experiências, a partir das quais possam vivenciar e/ou entender a lógica do outro, o trabalho teve como objetivo analisar o Cemitério Municipal da Irmandade da Santa Casa de São Gabriel e outros locais da cidade relacionados ao enterramento de pessoas, como a Capela dos Fuzilados a Capela dos "Noivinhos" e o Nicho Funerário com os restos mortais do Monsenhor Henrique Rech, na Igreja Matriz, através da leitura de sua história, como bens patrimoniais e através de seus atrativos e verificar a possibilidade de ações para a valorização do mesmo como roteiro turístico para o município.

\section{Metodologia}

A área de estudo ocorreu na cidade de São Gabriel, RS que surgiu em 1800, quando o espanhol Félix de Azara, ao chegar ao Cerro do Batovi, fundou a primeira povoação, de origem espanhola. Em 04 de abril de 1846, já no seu atual local - antiga Sesmaria da Trilha, com colonização portuguesa. Com a Lei Provincial n. ${ }^{\circ} 8$ de 04 de abril de 1846, São Gabriel foi elevada a categoria de município, com a instalação da Câmara de Vereadores, cujo presidente exercia o Poder Executivo sendo considerada a data de aniversário de sua emancipação (Figueiredo, 1980).

Em 1841 foi Capital da República Riograndense e, historicamente está ligada as armas, conhecida como "Terra dos Marechais", já que aqui nasceram os Marechais João Propício Menna Barreto, Fábio Patrício de Azambuja, o Presidente da República Hermes Rodrigues da Fonseca e João Batista Mascarenhas de Moraes, o Comandante da Força Expedicionária Brasileira na Segunda Guerra Mundial, durante as batalhas na Itália. Outros militares 
gabrielenses fizeram parte da história nacional, como o Coronel José Plácido de Castro, o desbravador que conquistou o Acre (São Gabriel, 2015).

A vocação militar conviveu pacificamente com a Poesia e outras artes, projetando para o Brasil o gabrielense Alcides Maia, o primeiro Gaúcho admitido na Academia Brasileira de Letras e o Padre Leonel Franca, teólogo fundador da PUC do Rio de Janeiro (São Gabriel, 2015).

A história política do município conta com personagens como o Castilhista Fernando Abbott, Presidente do Estado e o Embaixador Francisco de Assis Brasil, fundador e líder do Partido Libertador (São Gabriel, 2015).

O levantamento acerca do tema ocorre através de uma pesquisa exploratória e descritiva, onde o levantamento de dados secundários parte, tanto de fontes bibliográficas como documentais.

O recorte definido para este trabalho corresponde ao Cemitério Municipal da Irmandade da Santa Casa de Caridade de São Gabriel a qual foi fundada em 15 de abril de 1855 sob o nome de Santa Casa de Misericórdia. Em sessão solene realizada no dia 21 de julho de 1898 no Consistório da Igreja Matriz foi transferido da extinta Irmandade do Santíssimo Sacramento e Anjo Gabriel, para a Irmandade Santa Casa de Caridade, o Cemitério Municipal de São Gabriel. A entidade antes responsável havia recorrido à municipalidade, mas essa se negou a ficar com a direção do cemitério, cabendo a tarefa à Santa Casa, que a desenvolve até hoje.
Além disso, mais três locais fora do Cemitério foram analisados, a saber: A Capela dos Fuzilados junto ao $6^{\circ}$ Batalhão de Engenharia e Combate, A Capela dos "Noivinhos" na Rua Antônio Trilha e o Nicho Funerário com os restos mortais do Monsenhor Henrique Rech, na Igreja Matriz.

Para o desenvolvimento da pesquisa foram realizadas visitas "in loco" subsidiado por instrumento semiestruturado baseado em Nogueira (2013) com adaptações realizadas pelas autoras. Para melhor visualização e análise da potencialidade do local, foram analisados o grau de conservação e preservação, as tipologias presentes, a presença de pessoas ilustres ou ligadas as crenças populares além da infraestrutura como presença de arborização, arruamento, cercamento, presença de resíduos (flores secas, partes de caixões e até restos mortais expostos).

Nos outros três locais a avaliação se deteve ao acesso a estes locais, situação atual e registro de visitantes.

Após as visitas aos locais e análise dos mesmos somados ao embasamento bibliográfico foram discutidas as possibilidades para o desenvolvimento de atividades turísticas culturais com ênfase ao segmento cemiterial e místico.

A Figura 1 representa os locais de estudo e sua inserção na malha urbana de São Gabriel.

A Rua Duque de Caxias é considerada pelo Plano Diretor de São Gabriel (2008) como Centro Histórico Municipal ostentando vários elementos arquitetônicos representados por casarões, museus e prédios históricos (São Gabriel, 2008). 


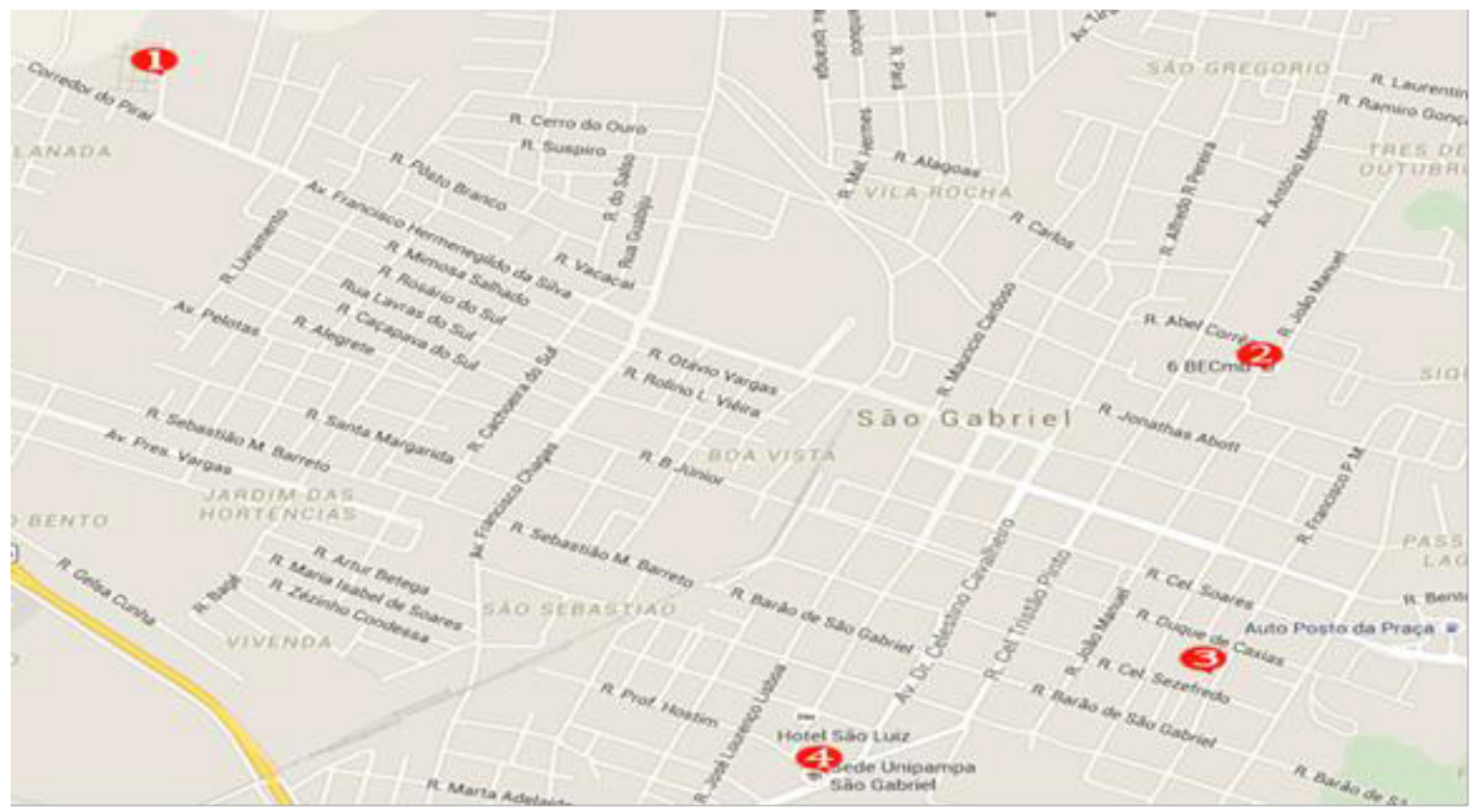

Figura 1 - Locais analisados com o intuito de estabelecimento de Turismo Cemiterial e Místico na cidade de São Gabriel, RS. 1 Cemitério; 2- Capela dos Fuzilados; 3- Igreja Matriz; 4- Capela dos "Noivinhos".

\section{Resultados e Discussão}

\section{Cemitério da Irmandade da Santa Casa de Caridade de São Gabriel}

As características iniciais observadas no Cemitério da Irmandade da Santa Casa de Caridade de São Gabriel é seu tempo de existência, ou seja, mais de um século e a divisão em duas alas: Ala Antiga e Ala Nova.
$\mathrm{Na}$ ala antiga estão os túmulos com maior importância histórica, arquitetônica e artística. No local encontramos túmulos com esculturas de anjos, crianças, figuras femininas, cristos, entre outras. A grande maioria dos jazigos, mausoléus ou túmulos foram construídas no início do século passado, em mármore branco, conforme Figuras 2A e 2B.

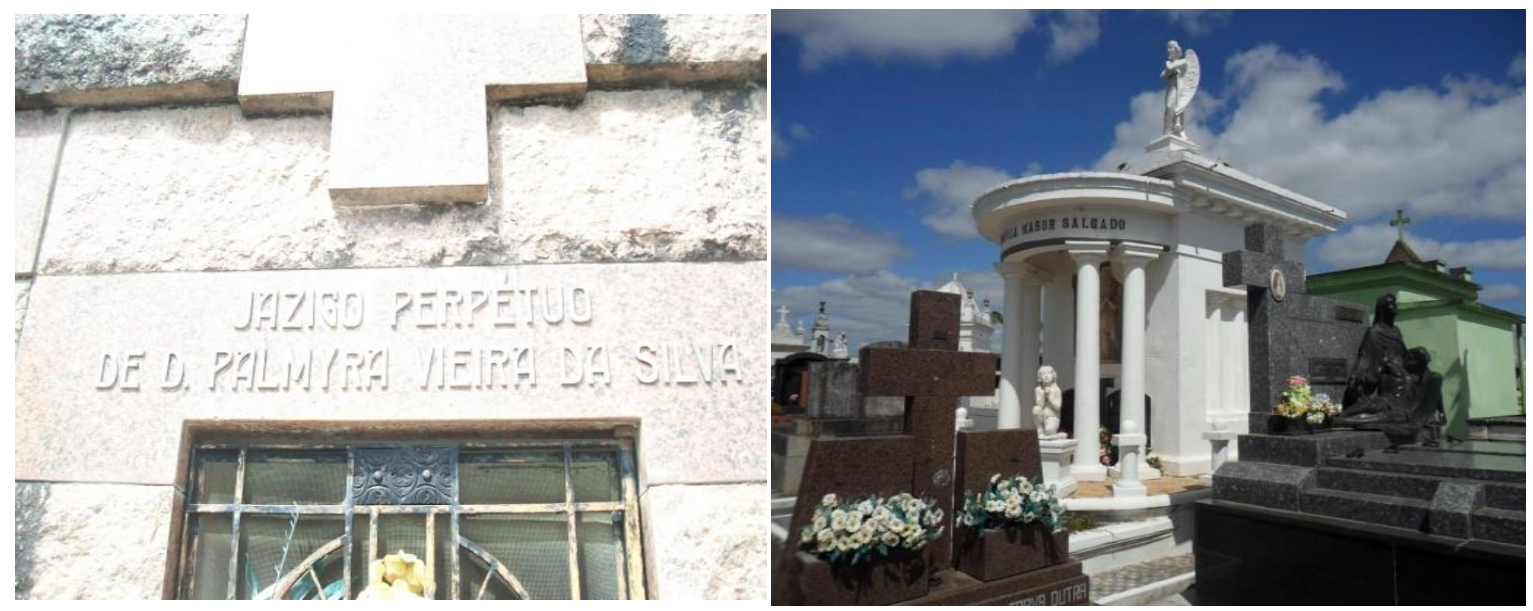

Figuras 2A e 2B - Mausoléus de família tradicionais no Cemitério da Irmandade da Santa Casa de Caridade de São Gabriel, São Gabriel, RS. 
O uso de mármore é justificado por Le Goff (1990) ao mencionar que "a pedra e o mármore serviam na maioria das vezes de suporte a uma sobrecarga de memória. Os arquivos de pedra acrescentavam à função de arquivos propriamente ditos um caráter de publicidade insistente, apostando na ostentação e na durabilidade dessa memória lapidar e marmórea".

Conforme Carvalho (2013) as esculturas femininas apresentam-se levando flores nas mãos, com expressões chorosas, caracterizadas pelo vestuário, geralmente longos mantos, e vários detalhes, como cintos, fivelas, presilhas, botões, fíbulas. Flores e plantas têm uma grande simbologia, pois representam de certa maneira a vitória. São ícones que vêm da Antiguidade, quando os soldados romanos eram recebidos com elas.

As esculturas funerárias participam de um segmento de arte pública, e são produtos genuínos de artistas e artífices, que cada vez mais tem obtido reconhecimento no repertório cultural das cidades. Ao investigar os cemitérios, encontramos uma parte relevante da história social da cidade, e aqui podemos sublinhar as marmorarias como participantes de uma rede atuante até a primeira metade do século XX (Carvalho, 2010).

A Figura 3 representa a expressão artística de uma réplica da Pietá encontrada em um dos túmulos do Cemitério.

Neste espaço observa-se a relação entre a arte e a morte, percebida através das formas, temas, materiais e sensibilidade de seus projetistas. Uma expressão artística disponível aos turistas para ser apreciada, analisada, estudada, mas, principalmente, respeitada. Estas formas se relacionam com o espaço criando fluxos e itinerários.

Conforme Costa (2013) a paisagem da morte, dotada de monumentalidade, possui funções, práticas, processos e formas singulares, que demarcam conjuntamente com ritos ou rituais, como os grupos sociais expressam seu poder socioeconômico e suas características culturais.

Em geral, observou-se que as construções tumulares estão muito alteradas no que se refere à preservação e em bom estado quanto à conservação.

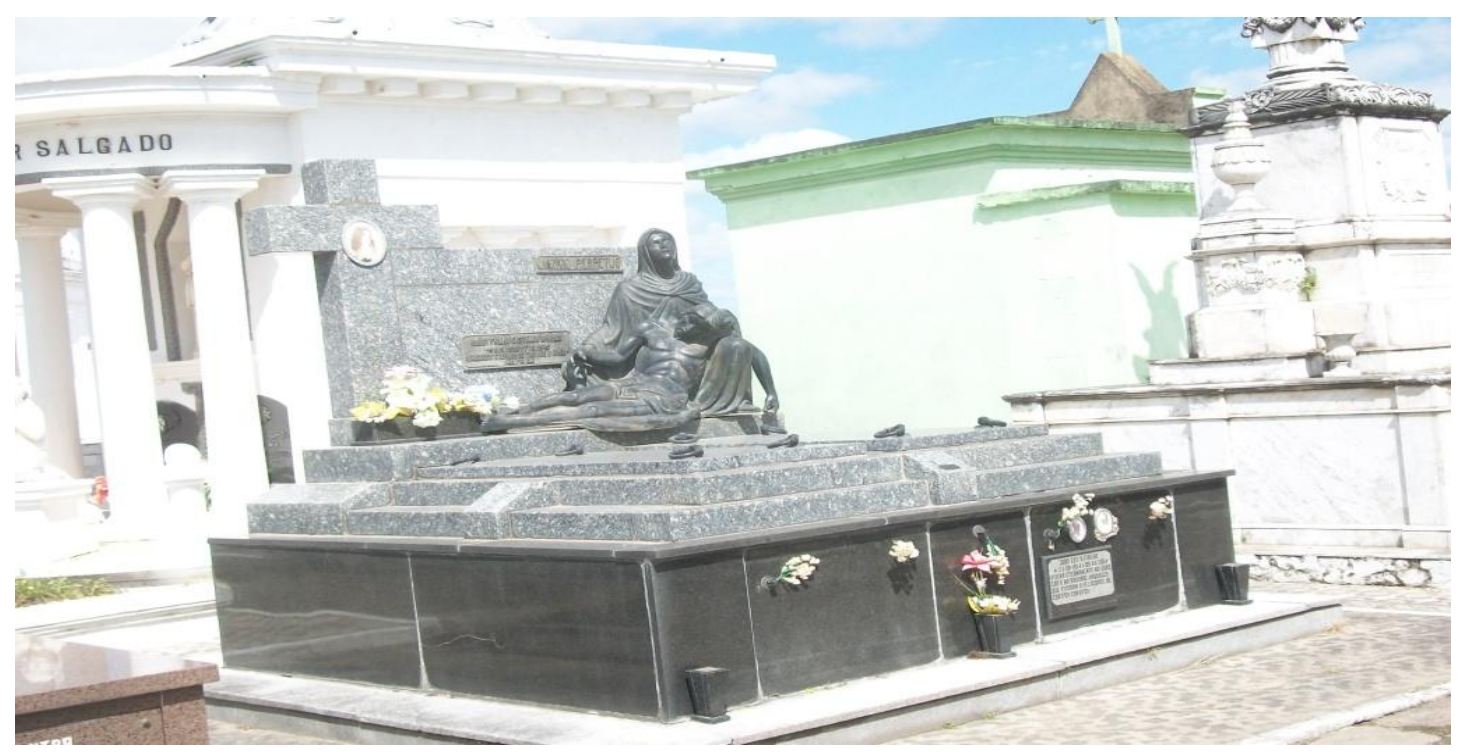

Figuras 3 - Expressão artística através de esculturas no Cemitério da Irmandade da Santa Casa de Caridade de São Gabriel, São Gabriel, RS 
Não foi observado presença de resíduos, como restos de caixões ou flores/coroas em decomposição. Estes resultados diferem da situação encontrada por Souza (2014) no mesmo local ao se deparar com uma grande quantidade de resíduos, inclusive com destinação incorreta, isto é, ao invés de serem incinerados eram colocados no lixo comum cujo destino final era o lixão.

Nesta ala há o predomínio de construções horizontais, onde, aproximadamente, metade delas são túmulos/sepulturas e a outra metade são mausoléus onde não se observa a presença de epitáfios.

Com relação à cenotáfio existem alguns em homenagem a heróis de guerra e vultos ilustres da comunidade gabrielense, somado a um Obelisco, na parte sul do Cemitério construído em mármore de misteriosa simbologia. A estranha alegoria tem a figura de uma serpente, um sapo, uma coruja, um besouro e uma borboleta, além de alguns elementos de certo misticismo que alguém talhou em relevo no mármore para instigar a curiosidade dos que buscam a verdade oculta a partir dos símbolos. Seu significado é uma incógnita (Figueiredo, 1980).

Este monumento foi transportado para a Praça interna da Irmandade da Santa Casa de Caridade de São Gabriel para sua preservação sendo que no Cemitério estava sendo depredado, porém hoje se encontra novamente no Cemitério, conforme Figura 4.

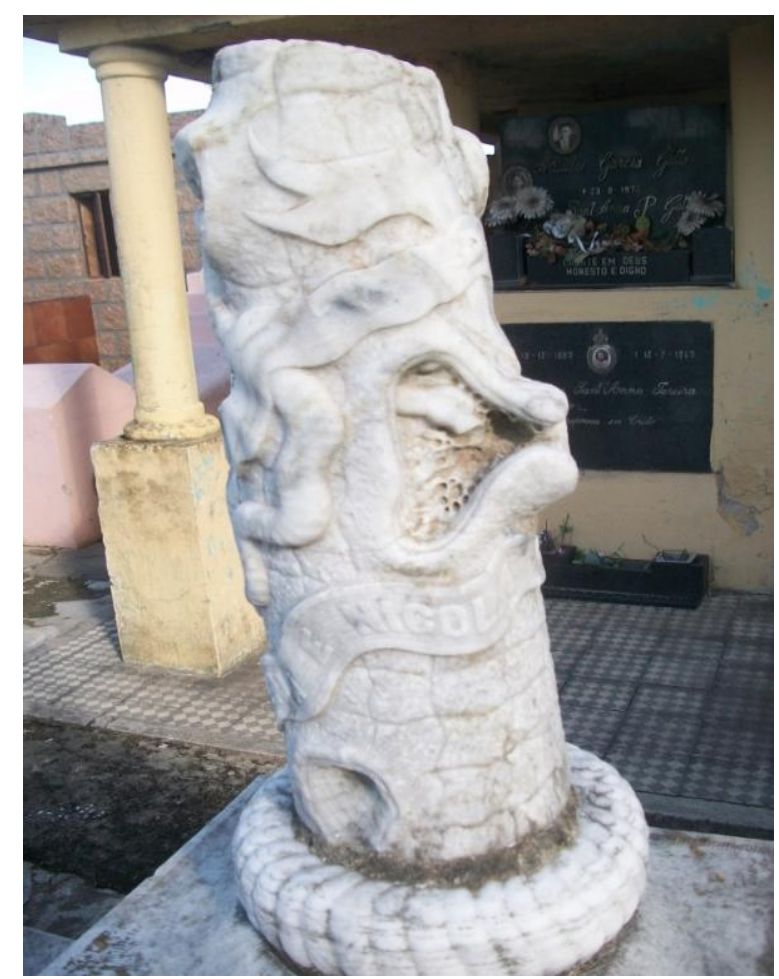

Figuras 4 - Monumento do tipo Obelisco no Cemitério da Irmandade da Santa Casa de Caridade de São Gabriel, São Gabriel, RS

Jazigos mais modernos foram construídos em pedra e são tão imponentes quanto os edificados em mármore com esculturas que caracterizam o estilo da época.

Algumas destas construções possuem também o busto esculpido identificando a última morada do de cujus ali sepultado, dentre os quais militares como o
Marechal João Propício Menna Barreto e o General Hipólito A. Ribeiro.

Construções mais modernas em mármore colorido e com adereços em metal, cruzes e imagens de Nossa Senhora e Jesus Cristo, também compõem enriquecem a paisagem melancólica do Cemitério. 
$\mathrm{Na}$ ala nova, a grande maioria das construções é vertical. Existem alguns jazigos com arquitetura mais moderna, grande parte do mesmo molde, alguns com materiais mais simples outros em mármore, pedra ou granito.

$\mathrm{Na}$ concepção de Nogueira (2013) a distribuição espacial nos cemitérios foi ligada as classes sociais, sendo que os mais onerosos e cobiçados se situavam às margens das alamedas centrais, cuja visibilidade era indiscutível, pois estes espaços eram destinados àqueles que podiam pagar por uma certidão de concessão perpétua, ou seja, um patrimônio que como outro qualquer pode ser passado de geração para geração. Por outro lado, os locais menos nobres, situados nas extremidades do espaço interno ou nas quadras transversais eram ocupados por jazigos mais simples, de famílias com parco poder aquisitivo.

Nesta ala todas as gavetas/carneiras ou construções novas estão identificadas/catalogadas, enquanto na ala antiga não há identificação por quadras ou por proprietário.

Embora na ala nova encontrem-se jazigos construídos de materiais nobres, nota-se com clareza a simplicidade das carneiras mal construídas em sentido vertical criando um contraponto entre a modéstia arquitetônica e o materialismo excessivo da outra ala. Mesmo que estes locais demonstrem a situação das famílias, ora com um jazigo à altura de sua posição, ora com uma simples sepultura, o destino de ambos é similar.

Em relação à infraestrutura do Cemitério não há arborização em seu interior, somente alguns arbustos surgem espontaneamente. Há arruamento parcial e a sua área é toda cercada, na sua maioria com muro.

Embora não constante no Plano Diretor de Desenvolvimento Urbano e Ambiental (PDDUA) segundo São Gabriel (2008), o local apresenta um grande potencial histórico e arquitetônico, embora muitas ações ainda devam ser efetuadas para criação de um roteiro turístico.
Dentre as alternativas possíveis para tornar o local com maior atratividade e aparência ressalta-se a limpeza das esculturas em mármore, hoje cobertas com limo, e o treinamento dos funcionários numa operação conjunta entre as Secretarias Municipais de Turismo e de Serviços Urbanos nestas tarefas básicas de manutenção de jazigos de valor histórico. Também os proprietários das sepulturas deveriam ser informados a respeito da proposta de manter este patrimônio e buscar o apoio deles e da sociedade em geral.

A ausência de manutenção, dentre outras causas, representa a deterioração do jazigo. Raízes de árvores e arbustos desestruturam as bases de construções mais antigas, e o crescimento da vegetação recobre jazigos e suas esculturas.

Um cemitério abriga em seu interior, os personagens históricos que desenvolveram as cidades, dedicando suas vidas ao progresso das mesmas. Estes locais sofrem com a descaracterização de seus acervos, por meio da ação da intempérie, da mão humana e, ainda do total desamparo, pois é inexistente uma ação de intervenção para a salvaguarda dos bens.

O problema da preservação de cemitérios enfrenta a questão da manutenção dos túmulos e do espaço cemiterial, cujos custos são atribuídos às famílias. Conforme Carvalho (2010) a partir da terceira geração, existe um crescente desinteresse por manter este tipo de bem, uma vez que se apresenta dispendioso e que é cada vez mais defasado o costume de se possuir um grande jazigo familiar.

Segundo o mesmo autor o processo de modernização das cidades sempre exigiu o sacrifício de incontáveis bens materiais e patrimoniais, muito deles sacrificados injustamente, pelo desconhecimento de seu valor autêntico. No caso da arte funerária, a situação é delicada, uma vez que a sua preservação depende do interesse da família em manter o túmulo, e do cemitério, em conservá-lo, angariando fundos e protegendo-o por meio das ações necessárias. 
Figuras populares enterradas no Cemitério de São Gabriel

Foi no fim do século $\mathrm{V}$, que conforme Bravo (2012) começou a haver a aproximação dos cristãos em relação às sepulturas dos santos e/ou mártires, com base na crença de que esta proximidade protegeria o corpo contra uma possível profanação do túmulo, e seria garantia de salvação aos mortos.

O Cemitério também possui alguns locais de peregrinação como o Jazigo da "Guapa" e o Túmulo da Ciganinha - personagens beatificados pelo povo.

A Guapa era forma como era conhecida a uruguaia Maria Isabel Hornos nascida a 15 de junho de 1897 que chegando em São Gabriel na década de vinte, estabeleceu-se, na avenida Dr. Celestino Cavalheiro, com pensão de mulheres. Muito bonita e amável com todos, carinhosa com as crianças, tornou-se popular e apreciada pela maioria da população. Possuía personalidade forte e corajosa, daí o apelido de Guapa. Em 03 de março de 1924, durante o carnaval, foi alvejada a tiros, pelas costas, no seu quarto. O culpado ficou impune, pois o crime teria sido "encomendado".
Seu sepultamento foi muito concorrido, pois sua morte consternou a cidade (São Gabriel, 2015).

O Túmulo da Cigana Anita localiza-se à esquerda do portão de entrada do Cemitério da Irmandade da Santa Casa de Caridade. Esta chamava-se Maria Anita Costichi, bela e formosa mulher de 40 anos de idade, muito alegre e gentil. No final de julho, seus admiradores souberam que estava muito doente recolhida a uma das tendas e, no dia 30 de agosto veio a falecer, vítima de câncer, após muito sofrimento (São Gabriel, 2015).

Estas duas figuras são consideradas santas populares e são reverenciadas por muitos que deixam muitos objetos nestes locais em agradecimento a graças alcançadas ou em homenagem aos falecidos que ali estão enterrados (Figura 5 A e Figura 5 B).

Neste sentido, segundo Thompson (2014) percebe-se que a existência dos túmulos e dos monumentos evoca a construção de rituais. Nestes dois casos dentro do cemitério atribuem-se milagres a estas duas personagens do imaginário popular observando-se em seus túmulos a presença de velas, flores, placas em agradecimento por graças alcançadas.

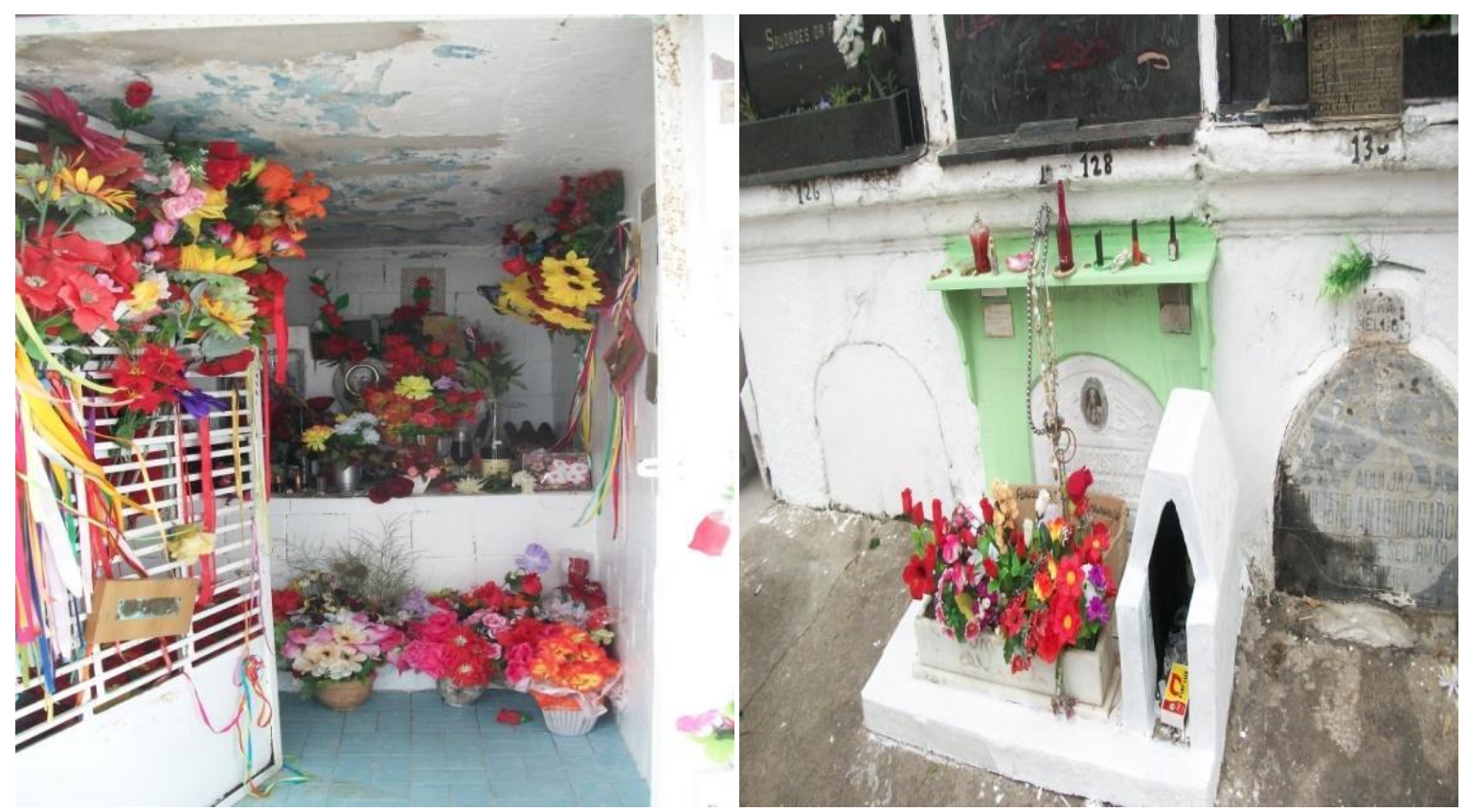

Figuras 5 - A- Capela da Guapa ornamentada com flores, velas e demais objetos. B- Capela da Cigana. Ambos os locais situados no Cemitério da Irmandade da Santa Casa de Caridade de São Gabriel, São Gabriel, RS. 
Outros locais de demonstração de fé

A realização do primeiro enterro extramuros de cemitérios no Brasil ocorreu no ano de 1775, segundo Pagoto (2004) envolvendo o corpo de uma escrava.

$\mathrm{Na}$ cidade de São Gabriel fora da área destinada ao cemitério temos alguns exemplos de cenotáfios, dentre os quais destaca-se a Capela dos Fuzilados, situada junto à parede externa da face meridional do quartel do $6^{\circ}$ Batalhão de Engenharia de Combate. Em abril de 1853 , o $1^{\circ}$ Regimento de Artilharia a Cavalo regressou para sua sede, em São Gabriel, vindo da vila de Jaguarão, trazendo um jovem condenado à morte. Com cerca de 17 anos, o soldado Agostinho José de Meira foi fuzilado no dia 08 de novembro de 1853 ao lado do quartel. Já a 14 de dezembro de 1855, foi executado, no mesmo local, Joaquim José dos Santos, praça do $1^{\circ}$ Regimento de Artilharia a Cavalo. Existe a crença que os dois teriam sido sepultados no mesmo local da execução, embora, na época, já existisse o cemitério da Vila Maria. Embora não fossem irmãos e as datas de suas execuções não coincidam os mesmos são denominados "Irmãozinhos Fuzilados".
Uma grande quantidade de placas, velas, santos e outros objetos permanecem no local, pois quando uma graça é alcançada, as pessoas colocam uma pequena placa de pedra, madeira ou outros objetos com as iniciais do seu nome e com o comunicado de que conquistaram à graça, conforme Figura 6 .

Conforme informado pelo Setor de Comunicação Social do $6^{\circ}$ Batalhão de Engenharia e Combate, onde está localizada a Capela em homenagem aos "Irmãozinhos Fuzilados", no ano de 2014, 11.623 pessoas visitaram o local, uma média de 968 pessoas por mês (Figura 6).

No interior da Igreja Matriz de São Gabriel encontram-se os restos mortais do Monsenhor Henrique Rech que, segundo Figueiredo (1980) foi a mais simpática e venerável figura religiosa que durante 70 anos viveu entre os gabrielenses (Figura 7).

Monsenhor Henrique Rech chegou a São Gabriel, a 3 de setembro de 1909. A Igreja Matriz estava por terminar. Durante 14 anos dedicou-se a conclusão deste templo.

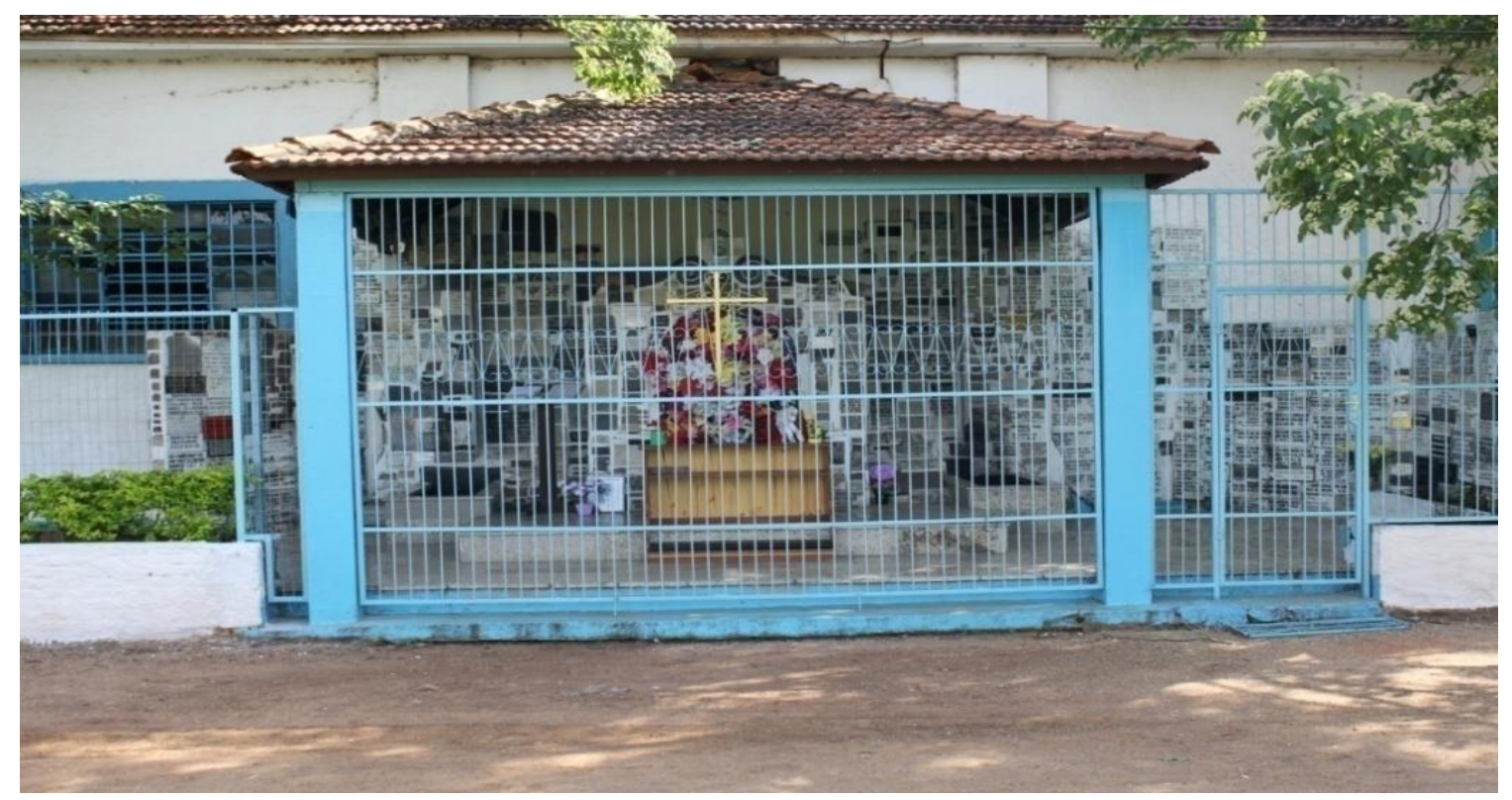

Figura 6 - Capela dos Fuzilados junto ao $6^{\circ}$ Batalhão de Engenharia de Combate. São Gabriel, RS 


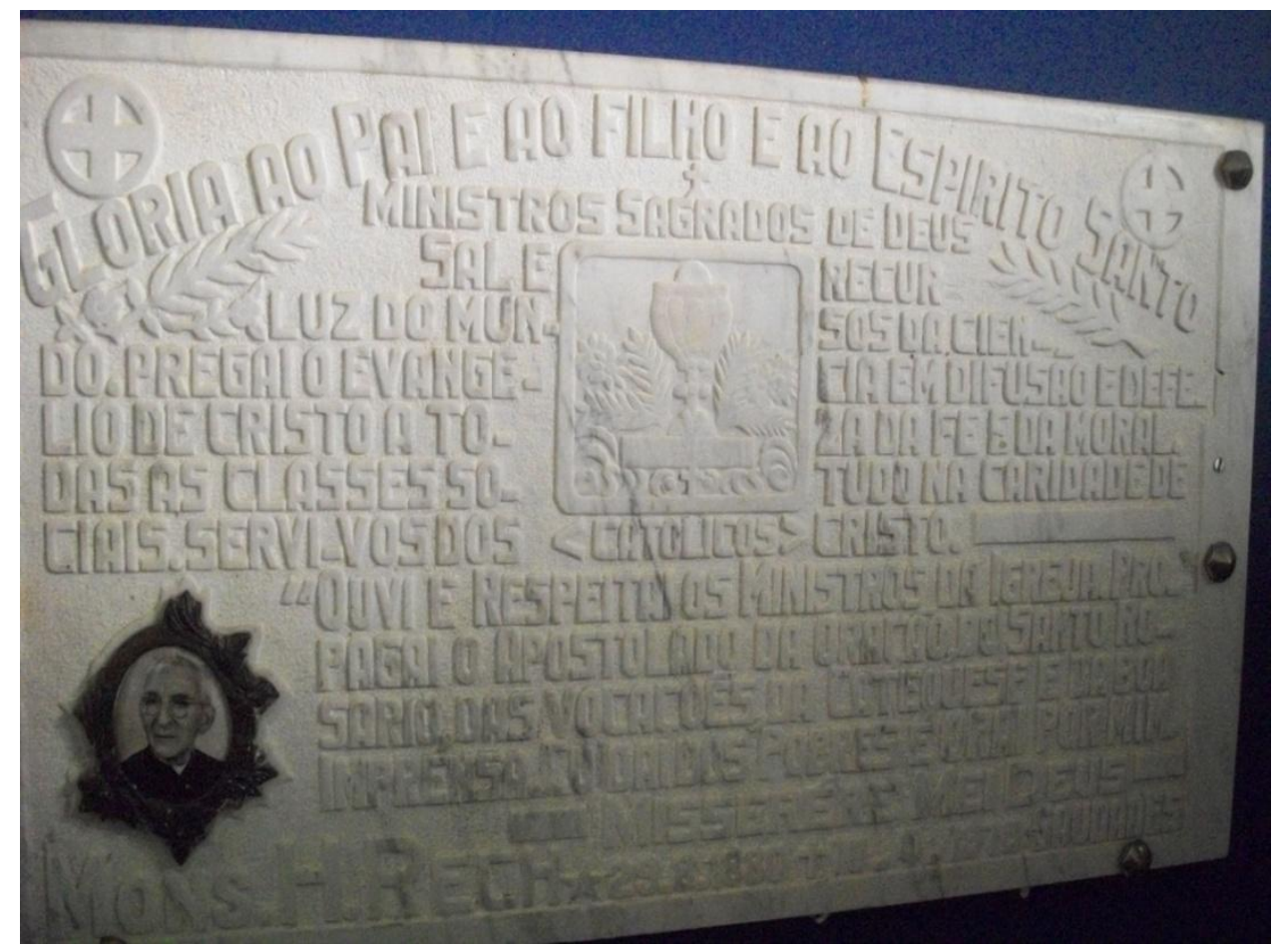

Figuras 7 - Epitáfio junto ao túmulo do Monsenhor Henrique Rech, Igreja Matriz de São Gabriel, São Gabriel, RS

Cumprindo sagrada vocação de obreiro de Deus, percorria o interior do município, às vezes a cavalo, outras de aranha, levando a todos os rincões a palavra confortadora de esperança e fé. Assim, foram surgindo as Capelas Distritais, além de outros locais de orações e instituições religiosas.

O prefeito Municipal decretou feriado municipal por três dias, escolas suspenderam as aulas e

o comércio fechou suas portas em homenagem ao santo homem que desaparecia do nosso convívio.

Ao se adentrar em São Gabriel, pela BR-290, verifica-se, ao lado da faixa asfáltica, em frente ao Estádio Municipal, um cenotáfio, denominado popularmente de capelinha (Figura 8). Naquele local, Cely de Castro Penteado, por apelido Hugo, e Irene Santos da Rosa, puseram termo à vida, ingerindo forte dose de veneno, adicionado a uma garrafa de guaraná (Figueiredo, 1993). Segundo Figueiredo (2009) passados não muitos anos, começaram a surgir no provável local às primeiras velas acesas e as primeiras flores, junto à cruz em intenção ao infortunado par de jovens, que os devotos apelidaram de "Noivinhos". Mais tarde um piedoso casal em cumprimento a uma promessa feita e atendida, mandou levantar um pequeno nicho em forma de igrejinha, onde o fervor da crença fez o oratório dos humildes que buscam pela fé e a proteção dos céus.

Estes locais indicam que o indivíduo, conforme Nogueira (2013) apesar de sua existência temporária pode após a morte, ser reverenciado e cultuado na memória ou na recordação de grupos específicos ou da sociedade como um todo 

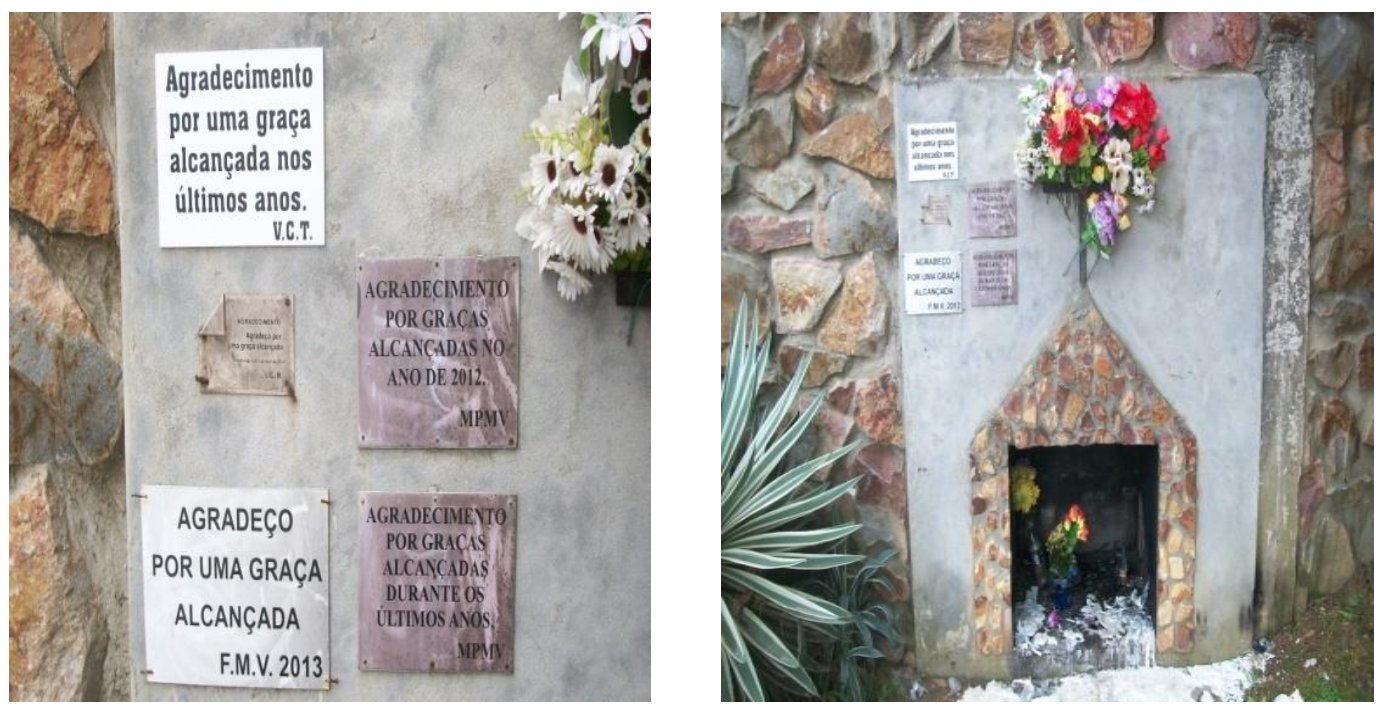

Figuras 8 - A Capela dos "Noivinhos" na Rua Antônio Trilha, São Gabriel/RS e placas no local em agradecimento a graças alcançadas.

\section{Potencialidades para o turismo}

Baseado no fato de que no momento em que os cidadãos passaram a ser enterrados em locais fora do âmbito das igrejas, denominados campos santos, o mesmo além de servir ao enterramento das pessoas, também passou a ser local de lazer, comercio e recreação e a visita aos cemitérios se tornou uma atividade mais comum, embora para muitos estes locais ainda estejam envoltos de medos e fantasias.

O turismo como fenômeno social, se facetou ao longo do tempo fazendo com que o patrimônio cultural passa a ser observado sob vários aspectos e com diferentes leituras. Dentre as vertentes turísticas surgiu o Turismo Cemiterial que busca não apenas a visita a jazigos de pessoas importantes, mas uma apreciação da arte, dos costumes e da história do local. O turismo cemiterial representa uma releitura da evolução social, histórica e econômica de certas comunidades.

O cemitério da Irmandade Santa Casa de Caridade possui potencialidade para desenvolver este segmento turístico, porém, a falta de visão e interesse do município faz com que este patrimônio se perca com o tempo, o que demonstra a falta de sensibilidade e de ações que possam incentivar a conservação do cemitério evitando sua degradação, o resgate de uma identidade local e regional e como forma de colaborar para a dinamização da economia local.

Para Figueiredo (2015) "para estabelecer e consolidar esta modalidade no Brasil é preciso um maior investimento e divulgação, assim como parcerias entre as esferas públicas e privadas, entre os cemitérios e a sociedade em geral. Necessita-se de uma informatização e catalogação dos monumentos, túmulos e esculturas tumulares das necrópoles, bem como a criação de panfletos com mapas, fotos e dados sobre a localização de tais túmulos, com as informações a respeito das personalidades sepultadas".

A fragilidade da vida faz com que a fé e a cultura mantenham uma profunda relação e se manifestem na religiosidade do povo e este diálogo com as crenças populares e nas devoções espontâneas são expressas nos votos (promessas) e nos ex-votos representando o agradecimento pelas graças alcançadas. Não nos cabe qualquer juízo de valor a respeito destas trocas simbólicas entre o humano e o divino ou ainda entre o plano terreno e o espiritual, porém representam uma fonte emergente para o turismo com viés cultural, místico e/ou religioso. 


\section{Considerações Finais}

O presente trabalho constitui-se em uma análise da situação do cemitério de São Gabriel como subsidio a uma proposta de implantação do Turismo Cemiterial, pois são nos cemitérios que se mesclam a memória coletiva de momentos distantes com o passado mais recente. A visita a estes locais incrementa a lembrança e por sê-la é lembrado e, esses mantêm vivo no meio social e exalta a ideia de continuidade.

Embora o interesse pelo turismo cemiterial seja ainda algo insipiente, sobretudo porque o seu estudo sistemático é recente e existe pouca conscientização da sociedade para o tema, porém ainda assim, representa uma possibilidade não somente de atração de turistas e geração de atributos econômicos, mas o da valorização de uma cidade inserida em uma região economicamente oprimida como os demais municípios que fazem partem da Metade Sul do Rio Grande do Sul, cujo enaltecimento somente recai no seu passado marcado por um futuro incerto e com a perda progressiva de sua memória.

Não somente a visita, mas o estudo sobre cemitérios nos permite compreender a sequência de processos sociais de cada sociedade, salientando-se a arte, a história e a cultura promovendo desta maneira o conhecimento da própria história da cidade.

Este estudo identificou caminhos que contribuem para conceber instrumentos de gestão que preservem o Cemitério, através da educação patrimonial, ou seja, o processo não formal de ensino e aprendizagem que deve ser implantado e dinamizado, pois se constitui em uma ferramenta de ensino que pode tornar-se objeto agregador no processo de aprendizagem corroborando com o despertar de uma consciência crítica e responsável pela preservação patrimonial e a percepção da relação entre os patrimônios e a identidade tanto pessoal quanto cultural.

As iniciativas que apresentam um cemitério como equipamento de turismo, para que tenham sucesso, necessitam desenvolver uma relação de pertencimento entre sociedade e o espaço, com a promoção de narrativas positivas que sejam transmitidas ao turista que busca esse local. Daí o reforço das ações intervencionistas no interior destes sítios, além de educação patrimonial para o grupo social em questão e fomento público às ações de turismo.

Os cemitérios traduzem aos vivos através de suas histórias, traços de dores, amores, saudades e medos, mas também materializam através de diferentes representações como velas, flores e placas uma forma de evocar sentimentos de fé, esperança e súplica como forma de evocar o passado no presente.

Até mesmo na morte detectamos traços de evolução, as diferentes classes sociais, a preservação da identidade ou o anonimato.

$\mathrm{O}$ apego religioso e/ou místico a pessoas da sociedade, nas suas diferentes manifestações demonstram uma afeição misteriosa e a criação de mitos do qual não se tem resposta. Será fruto do imaginário popular pessoas como a Guapa, a Cigana, os Noivinhos e os Irmãozinhos Fuzilados ou, efetivamente, representam um sentimento de conforto, espiritualidade e esperança entre a sociedade dos vivos e as cidades dos mortos?

É de se perguntar as razões pelas quais cidades que enfrentam problemas econômicos, ambientais e sociais e que detêm tamanho patrimônio inserido em sua malha urbana não despertem para os cemitérios não somente como lugares que apontam a vida social, valores e costumes de seus antepassados, mas patrimônios culturais que guardam a memória coletiva do lugar.

A possibilidade da exploração do cemitério de São Gabriel e demais locais relacionados neste estudo é possivelmente viável, porém há a necessidade de estudar e inventariar o patrimônio cemiterial existente; contribuir para a salvaguarda e proteção deste patrimônio; realizar restauros em obras danificadas; proporcionar investimentos de caráter público e privado, criar, dinamizar e qualificar a oferta turística e, principalmente, resgatar a consciência coletiva de preservação de seus bens. 


\section{Referências}

BRANDÃO, Carlos Rodrigues. "Cultura, Educação e Interação: observações sobre ritos de convivência e experiências que aspiram torná-las educativas" In: BRANDÃO, Carlos Rodrigues [et al.] "O difícil espelho: limites e possibilidades de uma experiência de cultura e educação". Rio de Janeiro: IPHAN, 1996.

BRASIL. (1937) "Decreto-Lei No 25, de 30 de novembro de 1937". Organiza a proteção do patrimônio histórico e artístico nacional.

BRASIL. (2008) “Constituição da República Federativa do Brasil" de 05 de outubro de 2008.

BRAVO, M. N. (2012) "Cemitérios (dos) desprivilegiados no Rio de Janeiro escravista". In: Disponível em: $<$ http://www.encontro2012.rj.anpuh.org/resources/ana is/15/1338426057_ARQUIVO_TextoANPUH-2012MILRAversaofinal $>$. Acesso em: 04/07/ 2015.

CARRASCO, G. L. de A. (2009) "Preservação de artefatos de ferros integrados à arquitetura". Estudo de caso: Cemitério do Imigrante- Joinville. $133 \mathrm{fl}$. Dissertação (Mestrado em Arquitetura e Urbanismo, Área de concentração Projeto e Tecnologia do Ambiente Construído, do Programa de PósGraduação em Arquitetura e Urbanismo - PósARQ) Universidade Federal de Santa Catarina - UFSC.

CARVALHO, L. F. N. (2010) "Entre a Lembrança e o Esquecimento: Implicações Do Descaso Patrimonial Para Arte Funerária Do Rio Grande Do Sul" Disponível em: http://www.anpap.org.br/anais/2010/pdf/chtca/luiza_f abiana neitzke_de_carvalho.pdf Acesso em: $12 / 11 / 2014$.

CARVALHO, L. F. N. (2013) “A melancolia e riqueza da arte cemiterial (I)" Disponível em: http://www.jornaldomercadopoa.com.br/index.php?op tion $=$ com_content\&view $=$ article\&id=936:amelancolia-e-riqueza-da-arte-cemiteriali\&catid=80: centro-historico\&Itemid=113 Acesso em: $12 / 11 / 2014$.

CASTRO, Elisiana. "Aqui também jaz um patrimônio: identidade, memória e preservação patrimonial a partir do tombamento de um cemitério (o caso do
Cemitério do Imigrante de Joinville/SC". Santa Catarina: UFSC/PGAU, 2008.

CHIAVENATO, J. J. "A morte: uma abordagem sociocultural”. São Paulo: Moderna, 1998.

COSTA, R. de O. (2013) "Práticas culturais e a urbe carioca: a análise do memorial das vítimas da ditadura militar no cemitério de Ricardo de Albuquerque - Rio de Janeiro/RJ”. Disponível em: www.simpurb2013.com.br. Acesso em: 04/07/2015.

DEL PUERTO, C. B.; BAPTISTA, M. L. C.; MÜLLER, D. (2014) "Espaço cemiterial como patrimônio e atrativo turístico". In: Seminário da Associação Nacional Pesquisa e Pós-Graduação em Turismo, 11, Fortaleza. Anais... p.1-18.

FIGUEIREDO, O. S. (1980) "São Gabriel desde o Princípio". Editora Palotti. Santa Maria- RS.

FIGUEIREDO, O. S. (1993) "História de São Gabriel”. Editora Palotti. Santa Maria- RS.

FIGUEIREDO, O. S. (1998) "Uma Santa Casa Feita de Amor”. Editora Palotti. Santa Maria- RS.

FIGUEIREDO, O. S. (2009) “Os Santos Populares". Editora Palotti .Santa Maria- RS.

FIGUEIREDO, O. M. (2015) "Turismo e lazer em cemitérios: algumas considerações". Revista CULTUR. Florianópolis. 9 (1)125-142.

http://www.goethe.de/ins/uy/prj/jug/pro/uruguay/Revista DM. (2015) "Descobrí Montevideo". Acesso em: $24 / 06 / 2015$

IPHAN- Instituto de Patrimônio Histórico, Artísitico Nacional. (2015) "Bens Tombados" Disponível em: http://portal.iphan.gov.br/portal/montarPaginaSecao.d o? id=13928\&retorno=paginaIphan. Acesso em:11/4/ 2015.

LE GOFF, J. (1990) "História e Memória". Editora da UNICAMP, Campinas, SP (Coleção Repertórios).

MENESES, U. T. B. de. (1996) “Os usos culturais da cultura. Contribuição para uma abordagem crítica das práticas e políticas culturais”. In: Yágizi, E. et al. (org). Turismo: espaço, paisagem e cultura. Hucitec, São Paulo. 
MONTEIRO, J. de O; SILVA, E. M. de C.; MONTEIRO, J. de O. (2010) "Turismo Macabro: Conhecer para Entender; Entender para (Des)construir". In: Seminário da Associação Nacional Pesquisa e PósGraduação em Turismo, VII, São Paulo.

NOGUEIRA, R. DE S. (2013) “Quando um cemitério é patrimônio cultural". Dissertação (Mestrado em Memória Social) - Universidade Federal do Estado do Rio de Janeiro, Rio de Janeiro.

PAGOTO, A. A. (2004) "Do âmbito sagrado da igreja ao cemitério público: transformações fúnebres em São Paulo (1850/1860"). Arquivo do Estado, Imprensa Oficial do Estado de São Paulo, São Paulo.

SÃO GABRIEL. Prefeitura Municipal. (2008) "Lei complementar $n^{\circ} 002$, de 2 de junho de 2008". Institui o Plano Diretor de Desenvolvimento Urbano e Ambiental de São Gabriel, dispõe sobre o desenvolvimento urbano no município de São Gabriel e dá outras providências. Disponível em: $<$ http://www.saogabriel.rs.gov.br/2013/comunidade/pl anoDiretor.html>. Acesso em: 13/07/ 2014.

SÃO GABRIEL. Prefeitura Municipal. (2015). Disponível em: <http://www.saogabriel.rs.gov.br/2013/site/index.html $>$ Acesso em 27/02/2015

SOUTO, L.R. (2013) "Relatório de Estágio no Cemitério Municipal da Irmandade da Santa Casa de Caridade de São Gabriel, RS”. Estágio Curricular (Bacharelado em Gestão Ambiental) - Unipampa, São Gabriel.

SOUZA, R.L. de. (2014) "Percepção ambiental dos moradores em relação ao convívio com o Cemitério da Irmandade da Santa Casa de Caridade de São Gabriel, RS". Trabalho de Conclusão de Curso (Bacharelado em Gestão Ambiental) - Unipampa, São Gabriel.

THOMPSON, B. (2014) "Memória e exaltação da vida no cemitério monumental". Revista SOCIAIS E HUMANAS, SANTA MARIA, 27 (03): 89 -107. 